\title{
How to Attack a Non-Strawman
}

A reply to the Andrew I. Cohen review of Escape from Leviathan: Liberty, Welfare, and Anarchy

Reconciled, in Ideas on Liberty, March 2002, $58-59$ (the review).

Primarily using philosophy, but also some social science, Escape from Leviathan (EfL) explains and defends what it calls an extreme version of the implicit 'classical liberal compatibility thesis': liberty, welfare, and anarchy are overwhelmingly complementary in normal practice (rationality is added for its intimate theoretical connections to these categories). This is done using theories, not definitions, of each concept. ${ }^{1}$ This important thesis is entirely positive. Therefore, somewhat unusually, all normative issues are avoided as irrelevant distractions in this context. In addition, the epistemology used is also unorthodox. A justificationist, or foundationalist, approach would be literally illogical: the self-refuting trilemma faced by 'supporting justifications' (as regards arguments and evidence) is of entailing infinite regresses, dogmatic starting points, or circularities. Consequently, critical rationalism is assumed: conjecture and criticism are all that is possible. ${ }^{2}$ Thus all aspects of the conjectured thesis are explained and defended from criticism as thoroughly as the book can encompass. It is concluded that the thesis has not been refuted and so may be critically preferred. (However, this could all still be viewed as a 'justification' by those thus inclined.) All of this is made clear enough in the short introductory chapter and repeated where relevant throughout. Yet some reviews do not have a firm grasp of the specific project and so reject it with unsound criticisms. We now turn to one such example.

This reply focuses on any disagreements with the review in the order in which they arise. There is no shortage of these, but not many are with what EfL actually says. It is always better to reply to criticisms of what is really argued. And it is even better to have those arguments refuted: for then we have progress. It would also be useful to have some page references, especially when the review attempts paraphrases of what EfL says. But we have to start from where we are.

The review begins with the observation that as EfL "focuses entirely on criticisms of libertarianism, a less felicitous but more descriptive subtitle would be: 'Against Arguments that Liberty, Welfare, and Anarchy are Incompatible" (58). Properly understood, the actual subtitle is not less accurate. How else can one attempt to reconcile these three things except by explaining how they are being theorised and dealing with arguments purporting to show that they cannot be reconciled? (The reconciliation remains conjectural, not established.) Perhaps the implication is that there could be some kind of supporting justification as a possible alternative way of reconciling them. But it is an explained assumption of the book that this is not an epistemological possibility. Hence, EfL attempts a reconciliation using the critical-rationalist method. But adding the epistemological method to the subtitle would seem to distract from the central thesis, as well as being unwieldy. ${ }^{3}$

How far is it right that EfL "applies Karl Popper's theory of knowledge to social theory"? It is certainly applying it to a particular thesis that includes aspects of social theory, but also many philosophical issues. Only in the section that tries to explain how Popper misinterprets the social and political implications of his epistemology (pp. 135-142) is it tackling social theory more broadly, however briefly (unfortunately, Popper eventually became too unwell to produce the reply to this section that he had once promised). It is not right that "on Popper's view, we ought to uphold theories that withstand efforts at disproof by critics" (emphases added). Rather, we may continue to conjecture that those theories might be true and continue to try to disprove them ourselves; but critics can aid us in this task. And rather than saying that EfL defends a "completely unregulated market", as the review asserts, it would be more accurate to say that it defends private-property anarchy-which is broader than market transactions - regulated by libertarian principles derived from the abstract theory (using freely-competing security and arbitration agencies when needed).

\footnotetext{
${ }^{1}$ Theories are about the world; definitions are about words. Only realistic theories can defend a thesis about the world.

2 'Criticism' here includes tests of all kinds. For detailed explanations of critical rationalism see, for instance, K. R. Popper, Conjectures and Refutations (London: Routledge \& Kegan Paul, [1963] 1978) and D. W. Miller, Critical Rationalism: A Restatement and Defence (Chicago and La Salle, Ill.: Open Court, 1994).

${ }^{3}$ However, the paperback (The University of Buckingham Press, 2012) now attempts to clarify matters with a subtitle of "Libertarianism Without Justificationism"-with "Rationality, Welfare, Liberty, and Anarchy Reconciled" as a sub-subtitle only within the book.
} 
We are told that EfL's "approach could furnish a weapon in the arsenal against anti-liberalism". This appears again to suggest, or hint, that it fails as a weapon for justifying or establishing "liberalism" (i.e., classical liberalism; more narrowly, libertarianism). But such a justifying weapon is not logically possible. It is possible to have conjectural explanations of how libertarianism should be understood and how it works. There are many such explanations throughout the book. And these could mistakenly be interpreted as 'supporting justifications'. However, for libertarianism to succeed it is necessary and sufficient that all the best anti-libertarian criticisms are generally accepted as being refuted (however, movements in the right direction are possible on a case-by-case basis).

EfL itself explains, but as the review puts it, that it moves with "considerable, sometimes blinding, speed against critics of liberalism". This is not only because, as the review correctly paraphrases, readers are free to check the original sources and any errors of interpretation might have remained even if dealt with at greater length. It is also because of the vast amount of criticism that needs to be covered to defend the compatibility thesis fairly comprehensively. If there are significant misrepresentations or errors in the responses, then it would have been better if the review explained, or at least cited, some of them rather than merely implying that they might be there. There does not seem to be anything wrong with "speed" as such. On the contrary, short and sweet refutations - if soundare an economy and a delight. Therefore, it seems a mistake to hold that brevity entails being "cursory" (superficially quick) in reviewing key arguments that "presuppose an intimate familiarity with scholarly criticisms of liberalism" without an example of where this is alleged to be a problem. In fact, it appears that the "layperson" - non-philosopher — can indeed get to grips with most of EfL: many correspondents have done so since its publication. It has not proven to be of "little value" to the non-philosopher just because there are some difficult patches. The review then suggests that EfL "has some value as an antianti-liberal guidebook". But what would be the use of a 'pro-liberal' book that ignores criticism? And does "guidebook" mean to imply that the replies to criticisms are seriously inadequate in themselves? If so, some alleged examples would be useful.

The review's exposition of EfL's a priori interpretation of homo economicus requires qualifications (these are all attempted paraphrases with no page references and no quotations from the book). We are told that "rational persons invariably calculate how best to promote their perceived interests". No, they do not perfectly calculate over time, but calculate as best they can given their current abilities and how they perceive the world and their interests at the time. And "persons rationally care for others" (p. 59) only to the extent that they are interested in those others as ends in themselves. It is not stated in EfL that "each of us acts by definition as a "purposeful maximizer"' (emphasis in review). It is argued (i.e., conjecturally explained) following the Austrian School of economics to be an a priori truth (or towards that end of the a priori-empirical spectrum, at least). While this argument is definitely held to be "non-moral and value-neutral" it is not exactly used in a "derivation of the market system," as the review states. It is used in various ways to defend the compatibility thesis. And, as critical rationalist epistemology is assumed in EfL, these cannot be the "foundations" that the review alleges they are intended to be. Note that throughout this reply we have various real errors of exposition and unsound responses; there is no objection to the mere "speed" at which this was done, of course. ${ }^{4}$

To be clear, EfL does not state or imply that outside of its particular thesis we can "dispense with the complexities of moral argument" for liberty (which the review restricts to "the market"). We are then told that EfL "stacks the deck by excluding certain considerations from counting as costs or benefits, so [it] can pretend this whole enterprise is purely descriptive". Which considerations are illegitimately excluded and in what way are they illegitimate? Replying to guesses as to what might be intended is likely to be a waste of time. And why allege that EfL must "pretend" (i.e., dishonestly purport) to be being descriptive rather than simply being mistaken? Isn't a mistake always more likely? And what would be the point of dishonesty here? In any case, isn't explaining — or at least specifyingthe alleged errors the only thing that is philosophically relevant?

The review goes on to allege one example of "robust evaluative work going on behind the scenes" when it says,

\footnotetext{
${ }^{4}$ For a more detailed, and recent, defence of an Austrian interpretation of Homo Economicus see "Adversus 'Adversus Homo Economicus': Critique of the 'Critique of Lester's Account of Instrumental Rationality' (https://philpapers.org/rec/LESAAH-2).
} 
This is clear in his effort to derive non-morally a system of ownership. But if property is taken to entail, as it usually does, a host of moral considerations, then we cannot derive a system of property simply from descriptive claims. (p. 59)

In other words, the review does not try to show the faults in the actual philosophical argument that attempts to derive property positively from applying the, also positive, abstract theory of liberty. ${ }^{5}$ Instead, it completely ignores the argument and falls back on its presuppositions. Why do anything so anti-philosophical? It then states that "Either the system of property he derives is of no normative consequence, or it involves the norms typically entailed by property and so is guilty of the naturalistic fallacy". Yes, the system of property is - and is intended to be - of no normative consequence in itself. EfL is not arguing here about what people ought to do but about what an abstract theory of libertarian liberty entails when applied. The compatibility thesis is positive and not normative. That hardly makes it unimportant or uninteresting.

The review then explains its own preferred approach: "Perhaps instead we should offer moral arguments to justify the consequences markets promote. This requires rolling up our sleeves and presenting some moral theory to undergird liberalism". There is certainly a place for moral arguments, but it is not while defending an objective thesis. There is never a place for trying to "justify" and "undergird" anything. The review merely ignores the epistemological arguments given in EfL for not attempting to do so. It would have done better to adopt a policy of "rolling up our sleeves and presenting some" precise philosophical analysis.

EfL does not defend "preference consequentialism" as a moral theory, as the review might appear to suggest, but only as a plausible theory of welfare. We are asked, "But what if aggregate preferences could best be satisfied by violating the rights of minorities? What protection does anarcholibertarianism offer?" However, EfL is only defending the thesis that in practice general preferences could not best be satisfied, overall and in the long-term, by infringements of liberty (not "rights of minorities"). The review does not offer any criticism other than this, ipso facto irrelevant, logical possibility that the thesis is mistaken. A similar confusion is found in the assertion that "Lester admits that he cannot in principle exclude horrific injustices" (with no page reference). Of course it is possible that liberty, welfare, and anarchy diverge radically "in principle" (or logically). The thesis being defended is that they do not significantly do so in reality. Only alleged real counterexamples are relevant to this.

It is next asserted, without a page reference, that EfL "claims that people happen to be constituted so that standard injustices are not preference satisfying, all things considered". What "standard injustices" are these? And how is this supposed to be related to how "people happen to be constituted"? It continues, "Such a response hinges long-term material prosperity, consonant with ordinary conceptions of justice, on a fragile preponderance of decent sentiments among the diverse lot of us". EfL does not defend any theory of "justice" or refer to anything like "decent sentiments" as being necessary. It does have many positive philosophical arguments. So what if "critics will be undaunted"? What does that have to do with the soundness of any argument in the book? What are the alleged "empirical claims about human psychology, and [...] normative suppositions lurking in the background of the whole project" (except those alleged about property, which have already been answered)?

As EfL is not about "showing that liberty can be an "uncontested concept"" it is hardly a fault that the book does not do so. On the contrary, it is entailed by critical rationalism that all concepts are contestable - even logical and mathematical ones. There is no "project of defending the market against charges of theoretical inconsistency". The "project" is philosophically defending the positive compatibility of liberty, welfare, and anarchy in practice.

Finally, it is a sort of confused understatement that, as the review concludes, "giving critics of libertarianism a run for their money can be an important and powerful buttress to the regime of liberty". If we include all inconsistent theories, including moral ones, as implicit 'critics' (or, rather, criticisms), then there is nothing else we can usefully do (or if there is the review does not explain what it is). However, libertarianism - whether considered positively as in EfL, or normatively as the review prefers - cannot have a supporting "buttress": it can only be a conjecture to be explained and defended.

\footnotetext{
5 For a more recent and probably clearer explanation see Lester, J. C. 2022. "Eleutheric-Conjectural Libertarianism: a Concise Philosophical Explanation", PhilPapers: https://philpapers.org/rec/INDNLA.
} 
(August, 2002; revised January 2022.) 